\title{
CRESCIMENTO RELATIVO E TAMANHO DE MATURIDADE SEXUAL DE DUAS ESPÉCIES SIMPÁTRICAS DE BIFFARIUS MANNING AND FELDER, 1991 (DECAPODA, AXIIDEA, CALLIANASSIDAE) EM UMA PRAIA URBANA NO NORDESTE DO BRASIL
}

\author{
Marinho, N.C.M. ${ }^{1}$; Costa, L.B. ${ }^{1}$; Carvalho, P.V.V.C. ${ }^{1}$ \& Botter-Carvalho, M.L. ${ }^{1, *}$ \\ ${ }^{1}$ Universidade Federal Rural de Pernambuco (UFRPE), Campus Recife, Laboratório de Ecologia \\ do Bentos Costeiro (LEBENC), Departamento de Biologia. \\ *Autor correspondente: monicabotter@yahoo.com.br
}

\begin{abstract}
O presente trabalho tem como objetivo analisar o crescimento relativo e determinar o tamanho de maturidade sexual morfológica em populações simpátricas dos camarões fantasma Biffarius fragilis (Biffar, 1971) e B. biformis (Biffar, 1970). Os animais foram coletados em um banco areno-lamoso na praia de Casa Caiada (Olinda, Pernambuco) $\left(7^{\circ} 58^{\prime} 59.87^{\prime \prime} \mathrm{S}\right.$ e $\left.34^{\circ} 50^{\prime} 6.08^{\prime \prime} \mathrm{O}\right)$, entre os anos de 2012 e 2014 . Para cada indivíduo foram tomadas as seguintes medidas: comprimento da carapaça (CC), comprimento total (CT) e comprimento do propódio do quelípede maior $(C P)$. O crescimento relativo foi descrito pela equação alométrica $\left(Y=a X^{b}\right)$. O tamanho de maturidade sexual foi determinado através da análise do padrão de crescimento alométrico do propódio do quelípede maior. Foram obtidos 720 indivíduos de $B$. fragilis (359 machos e 361 fêmeas), e 163 de B. biformis (83 machos e 80 fêmeas). Para $B$. fragilis a relação entre o CC e CT indicou crescimento alométrico negativo, para machos e fêmeas e entre juvenis e adultos. Enquanto que para $B$. biformis, foi verificado um crescimento alométrico negativo para machos (juvenis e adultos), e para as fêmeas da população. A relação entre CC e CP para $B$. fagilis indicou um crescimento alométrico positivo para fêmeas (jovens e adultas) e para machos jovens, e isométrico para machos adultos. Os machos de $B$. biformis apresentaram crescimento alométrico negativo para juvenis e alométrico positivo para adultos. As fêmeas e machos de $B$. fragilis atingem a maturidade sexual morfológica com tamanhos semelhantes ( $C C=3,1 \mathrm{~mm}$ e $3,2 \mathrm{~mm}$, respectivamente). Os machos de $B$. biformis alcançam o tamanho de maturidade sexual aos $3,4 \mathrm{~mm}$ e as fêmeas com 3,36mm de CC.
\end{abstract}

Palavras-chave: Crustacea, camarões escavadores, maturidade morfológica, crescimento. 